Rev. Interd. em Cult. e Soc. (RICS), São Luís, v. 7, n. 2, p. 207- 213, jul./dez. 2021

ISSN eletrônico: 2447-6498

\title{
Dilemas e alternativas do uso das redes e mídias sociais no processo de aprendizagem $^{1}$
}

\section{Dilemmas and alternatives of the use of social media and networks in the learning process}

CAIO SOUTO

Professor Efetivo de Filosofia do Instituto Federal do Amazonas (IFAM), Campus Presidente Figueiredo/AM. caiosouto@gmail.com

IASMIM MARTINS

Professora convidada da PUC-Rio, professora convidada dos cursos de MBA da FGV e professora do ensino básico no Estado do Rio de Janeiro (SEEDUC)

iasmim.martins98@gmail.com

\section{RESUMO}

O texto parte de uma constatação das limitações do uso das mídias digitais e das redes sociais no âmbito educacional, especialmente considerando-se um país tão desigual como o Brasil. Em seguida, contudo, abordamos certos modos possíveis de ações propositivas cuja raiz se encontra na situação de crise sanitária provocada pelo novo coronavírus, partindo de experiências concretas com a docência, com o atendimento clínico e com o uso das mídias digitais e das redes sociais.

Palavras-Chave: Redes sociais. Coronavírus. Mídias digitais. Clínica. Neoliberalismo.

\begin{abstract}
This text begins from a constatation about the limits of the use of digital media and social networks in the educational scope, especially considering a country as unequal as Brazil. Then, however, we address certain possible modes of propositional actions that are rooted in the situation of health crisis caused by the new coronavirus, starting from concrete experiences with teaching, with clinical care and with the use of digital media and social networks.
\end{abstract}

Keywords: Social networks. Coronavirus. Digital media. Clinical care. Neoliberalism.

De uma década para cá, o interesse dos pedagogos, filósofos, historiadores e sociólogos da educação pelas transformações ocorridas com a chamada Quarta Revolução Industrial ou Revolução Digital tem crescido exponencialmente. A grande

\footnotetext{
${ }^{1}$ Artigo submetido para avaliação em 26 de agosto de 2021 e aprovado em 13 de novembro em 2021.
} 
Rev. Interd. em Cult. e Soc. (RICS), São Luís, v. 7, n. 2, p. 207- 213, jul./dez. 2021 ISSN eletrônico: $2447-6498$

inovação trazida pela Indústria 4.0 é a de que sistemas operacionais podem tomar decisões com base numa racionalidade algorítmica de modo quase instantâneo, assim como solucionar problemas informacionais com enorme flexibilidade (PREVITALLI \& FAGIANI, 2020). Deste modo, não apenas as produções mecânicas passam a ser automatizadas, mas também certos tipos de atividade mental humana passam a ser substituídos por operações automatizadas. Ninguém nega que tais inovações poderiam auxiliar, caso sejam bem empregadas, na resolução de diversos problemas existentes em nossa sociedade. Porém, e sobretudo em países como o Brasil, onde há uma enorme desigualdade de acesso aos dispositivos digitais e mesmo à internet, elas também contribuem para agravar esses mesmos problemas.

Sabemos que o Banco Mundial, a Organização Mundial do Comércio e a Organização para a Cooperação e o Desenvolvimento Econômico, entre outros órgãos, pressionam os sistemas de educação nacionais a fazer com que as instituições de ensino e os profissionais que nelas trabalham se moldem às necessidades do capitalismo contemporâneo (JOURDAN, 2020). De fato, o campo da educação vem sofrendo gigantesca pressão de grandes grupos empresariais pela implantação do sistema de ensino à distância, e o acontecimento da pandemia acelerou sensivelmente um processo que já estava em curso. Como nos demais campos de nossa vida social, a educação vive o dilema entre ser um serviço prestado a clientes ou uma potência emancipatória. Muito se discutiu a respeito do modelo escolar, desde sua arquitetura até a relação mestrealuno que ela encerra. Algo semelhante passa a ocorrer na era da digitalização do ensino, e mais uma vez se trata de um processo que possui uma dinâmica global, mas cujos efeitos só podem ser avaliados singularmente caso a caso. No âmbito francês, por exemplo, dando continuidade à crítica do neoliberalismo iniciada por Michel Foucault, a obra de Christian Laval (LAVAL, 2019; LAVAL \& DARDOT, 2016) tem sido uma referência. Contudo, no caso brasileiro, há outras decorrências do modelo neoliberal cuja singularidade não se pode negligenciar (GALLO \& CARVALHO, 2020; KOHAN, 2021).

Como dissemos, esse processo possui uma dimensão global, quando se compreende a Revolução Digital como a mais recente das etapas de um processo genericamente concebido como a "modernização" de todas as instituições-base que 
Rev. Interd. em Cult. e Soc. (RICS), São Luís, v. 7, n. 2, p. 207- 213, jul./dez. 2021 ISSN eletrônico: $2447-6498$

compõem a economia de mercado capitalista em seu modelo concorrencial, o que inclui também os sistemas de produção e de difusão de conhecimento (ROSA, 2019, p. XXXIX). Contudo, como os seus efeitos são sentidos singularmente em cada caso particular, este texto resulta de uma reflexão crítica feita por dois docentes a partir de suas próprias experiências em níveis de ensino diversos (ensino médio, superior e pósgraduação) em três cidades que apresentam realidades muito diferentes: Macapá (capital do estado do Amapá, com IDH de 0,733), Presidente Figueiredo (cidade situada há $130 \mathrm{~km}$ da capital do Amazonas, com IDH de 0,647) e Rio de Janeiro (capital fluminense, com IDH de 0,796) $)^{2}$.

Os resultados dessas transformações impostas na atividade docente, e também na subjetividade da(o) docente, variam muito, a depender de diversos fatores, tais como: tipo de vínculo do profissional da educação (se temporário, contratado, em estágio probatório, efetivo, celetista ou "pejotizado"), tipo de instituição (pública, privada ou mista), grau de oferecimento do ensino (fundamental, médio, superior, tutoria, pósgraduação), gênero e idade da(o) docente; região do país ou mesmo dentro de uma mesma cidade; acessibilidade dos alunos; etc. Das agruras muitas vezes decorrentes da situação precária a que está submetida grande parcela desses trabalhadores, derivam também novas formas de adoecimento psíquico, efeitos de fatores que podem ou não conjugarem-se entre si, tais como: má remuneração ou atraso de recebimentos, sensação de substitutibilidade, insegurança, falta de reconhecimento, síndrome de Burnout por acúmulo de dois, três ou às vezes até um número maior de empregos, sensação de trabalho ininterrupto, avaliação pormenorizada e individualizada do desempenho, entre outros. Além disso, é necessário ainda "interseccionalizar" (COLLINS \& BILGE, 2021) as eventuais discriminações sofridas pela(o)s profissionais de educação em nosso país, para realizar um exame mais detido sobre as consequências possivelmente advindas da implantação do teletrabalho: no caso do gênero, as mulheres são as que ficam com a carga mais pesada, sobretudo quando são mães (basta ver os dados sobre o número assustadoramente maior de mulheres do que de homens que perderam seus empregos

\footnotetext{
${ }^{2}$ Caio Souto trabalhou como docente na Universidade do Estado do Amapá até janeiro de 2021, quando assumiu posse no Instituto Federal do Amazonas, encerrando seu vínculo anterior. Todos os atos de encerramento do contrato anterior, bem como os de posse e início de exercício no subsequente ocorreram remotamente. Iasmim Martins, durante a redação deste artigo, está exercendo a docência remota tanto na escola estadual quanto nas pós-graduações nas quais leciona (PUC-RJ e FGV).
} 
Rev. Interd. em Cult. e Soc. (RICS), São Luís, v. 7, n. 2, p. 207- 213, jul./dez. 2021 ISSN eletrônico: 2447-6498

durante a pandemia); assim também os idosos, pois os mais jovens assimilam melhor a interatividade, e com ela a competitividade; além dos demais elementos já citados acima.

É verdade, porém, que os dispositivos digitais favoreceram a continuidade do ensino num momento em que ainda não é possível (enquanto o texto é escrito) retomarmos, com segurança, as aulas presenciais. Sem que os houvesse, seria impossível fazer chegar aos alunos o material de ensino produzido, bem como certas dinâmicas que podem ocorrer em plataformas como o Zoom, o GoogleMeet, ou similares. Contudo, regiões rurais afastadas, e até mesmo em grandes cidades, o percentual de alunos que possuem acesso ininterrupto à rede de internet, e que poderiam acompanhar a um inteiramente online, é muito pequeno, podendo chegar a menos de $50 \%$ em alguns casos. Assim, uma das soluções encontradas para oferecer o melhor possível do conteúdo lecionado aos demais alunos é a rota itinerante, que entrega semanalmente o material físico impresso aos alunos, recolhendo as avaliações e exercícios. Modelos como esse ocorrem nos Institutos Federais ao redor do país, e também em outras instituições de ensino. Tais exemplos deveriam bastar para nos convencer de que, por si só, as inovações digitais não podem trazer ganho inequívoco em matéria de educação pública num país como o Brasil. Uma inovação que deveria, em princípio, facilitar a inclusão acaba por excluir os menos favorecidos, isto é, aqueles que mais precisam.

Estamos, pois, diante de um incomensurável desafio. Mas grandes momentos de crise ensejam também grandes transformações efetivas. Em nosso caso, essa transformação não poderá ocorrer desvencilhada de uma profunda reflexão crítica a respeito do que é a escola, do que é o ensino, do que são os dispositivos digitais e do que é o capitalismo. Quando Foucault escreveu "onde há poder, há resistência", é porque pensava que era necessário, para resistir ao poder, sermos tão inventivos quanto ele. Do contrário, jamais deixaríamos de ter uma postura meramente reativa aos acontecimentos que nos são externos. Nesse sentido, o tempo de um ano e alguns meses de pandemia no Brasil já nos revelou diversas possibilidades, e também alguns dos limites do uso das mídias digitais no âmbito da educação num país como o Brasil, dos quais falamos brevemente acima. Falemos agora um pouco dessas possibilidades. 
Rev. Interd. em Cult. e Soc. (RICS), São Luís, v. 7, n. 2, p. 207- 213, jul./dez. 2021 ISSN eletrônico: $2447-6498$

Para pensarmos uma apropriação positiva das mídias e redes digitais, não devemos nunca pensar em termos de substituição do espaço escolar ou da dinâmica que lhe é correlata. Se é verdade que todo acontecimento impede uma reversão ao estado anterior, é igualmente verdadeiro que o novo estado também não substitui aquele, mas sim afirma a sua diferença para com ele. Nesse sentido, se quisermos fazer da crise um propósito, se quisermos resistir a esse novo estado ao qual estamos submetidos, isso talvez signifique reconhecer os campos de novas possibilidades e de novas lutas que ele mesmo também abre. Pois se as mídias e redes digitais não podem contribuir genericamente no processo de aprendizado, seja por falta de acesso de grande parte dos alunos, seja sobretudo por se constituírem como aporte a um modelo neoliberal que quer se apropriar do modelo escolar, elas podem contribuir sob condições específicas. É necessário, então, criar essas condições.

Uma ideia que julgamos ter sido inovadora, no sentido de abrir novas possibilidades de utilização dos dispositivos digitais, foi a criação do canal do YouTube “Conversações Filosóficas". Ainda no mês de março de 2020, logo quando começaram as primeiras interrupções de ensino presencial no país em decorrência da pandemia de coronavírus, o canal foi criado com a proposta de abrir um espaço de escuta de pesquisadoras e pesquisadores de diversas áreas do conhecimento, com ou sem vínculo acadêmico, de todas as regiões - e depois estados - do país. É como se tentássemos provocar, em meio às redes digitais que já possuem certa predisposição de tempo e de resposta para cada vídeo e para cada frame, uma espécie de interrupção. Cremos ser, hoje mais do que nunca, necessária uma intervenção, no sentido que lhe deu Isabelle Stengers:

[...] aquilo que experimentamos quando, durante um debate, um participante toma a palavra e apresenta o que está sendo debatido 'de uma maneira um pouco diferente', provocando uma pequena pausa. Depois, claro, o debate continua como se nada tivesse acontecido; mais tarde, porém, alguns dos presentes que estavam escutando mostrarão que foram tocados (STENGERS, 2015, p. 5).

Muitos outros Canais, Blogs, Podcasts, perfis de Instagram, Twitter ou Facebook acrescentaram-se aos que já havia desde mais tempo, o que criou uma dinâmica nova nas redes sociais, ao menos no que tange às áreas específicas de 
Rev. Interd. em Cult. e Soc. (RICS), São Luís, v. 7, n. 2, p. 207- 213, jul./dez. 2021 ISSN eletrônico: 2447-6498

filosofia, psicanálise e humanidades de um modo geral, com as quais estamos mais familiarizados. Claro que há o perigo de que essa rápida proliferação de novos veículos digitais de divulgação e de debate logo gere um ambiente de competição entre os criadores de conteúdo. Também pode ocorrer uma especialização em diversos canais reunidos cada um em torno de um assunto, apenas reproduzindo a lógica dos grupos consolidados. Contudo, pensamos que há caminhos a serem abertos dentro desse novo campo de possibilidades, e que se esses canais não ficarem restritos apenas aos que "já têm o que dizer" e aos que já sabem o que querem escutar, teremos alcançado algum objetivo maior.

Por fim, cabe dizer uma palavra com relação ao papel das humanidades num período como o nosso e, ainda mais especificamente, à psicanálise e à filosofia. A escuta, o cuidado e a elaboração das perdas e do luto em situações-limite são tarefas para as quais a psicanálise ainda tem muito a contribuir, num cenário tão devastador como o que estamos vivenciando. E tem sido necessário repensar também algumas dessas práticas de escuta a partir dos dispositivos digitais, o que força a uma reflexão crítica a respeito da flexibilização de certos pressupostos da atividade clínica. A elaboração conceitual, e o rigor que lhe é caro, por sua vez, são tarefas imprescindíveis para refletirmos sobre a situação que ora se nos coloca. Ela é imprescindível tanto para analisarmos o momento pandêmico e as implicações que ele nos acarreta e submetê-las a um exame crítico, quanto para pensarmos a utilização dos meios digitais e das redes sociais nesse mesmo contexto, o que se torna um pouco mais delicado quando pensamos no caso da educação. Não há nem jamais haverá "novo normal". O que se pode identificar na história é um "processo de normalização" simultaneamente ao qual existem lutas parciais e singulares que resistem a esse processo e que buscam interrompê-lo, lutar contra ele, isto é, criar a partir das condições que ele a cada tempo enceta novas possibilidades de vida. Nesse sentido, pensar a utilização dos meios digitais no âmbito da educação num contexto como o nosso é, sem dúvida, uma das tarefas - e não a mais simples de ser feita - de uma reflexão crítica do presente. 
Rev. Interd. em Cult. e Soc. (RICS), São Luís, v. 7, n. 2, p. 207- 213, jul./dez. 2021 ISSN eletrônico: 2447-6498

\section{REFERÊNCIAS}

COLLINS, Patricia Hill; BILGE, Sirma. Interseccionalidade. Tradução Rane Souza. São Paulo: Boitempo, 2021.

GALLO, Silvio; CARVALHO, Alexandre Fiorde de. "Foucault e a governamentalidade democrática: a questão da precarização da educação inclusiva". IN: Mnemosine, Vol.16, no 1, p. 146-160 (2020), p. 146-160.

JOURDAN, Camila. "2020: Distopia, necropolítica e revolta". IN: Calibán: revista latino-americana de psicanálise, vol. 18, 2020 pp. 173-180.

KOHAN, Walter. "Tempos da escola em tempo de pandemia e necropolítica". IN: Práxis educativa, Ponta Grossa, v. 15, 2020, p. 1-9. Disponível em: https://www.revistas2.uepg.br/index.php/praxiseducativa. Acesso em 25/04/2021.

LAVAL, Christian; DARDOT, Pierre. A nova razão do mundo: ensaio sobre a racionalidade neoliberal. Tradução Mariana Echalar. São Paulo: Boitempo, 2016.

LAVAL, Christian. A escola não é uma empresa: o neoliberalismo em ataque ao ensino público. Tradução Mariana Echalar. São Paulo: Boitempo, 2019.

PREVITALLI, Fabiane Santana; FAGIANI, Cílson César. "Trabalho digital e educação no Brasil". IN: ANTUNES, Ricardo (org.). Uberização, trabalho digital e indústria 4.0. São Paulo: Boitempo, 2020, p. 328-356.

ROSA, Hartmut. Aceleração: a transformação das estruturas temporais na Modernidade. Tradução Rafael H. Silveira. São Paulo: Editora Unesp, 2019.

STENGERS, Isabelle. No tempo das catástrofes. Tradução Eloísa Araújo Ribeiro. São Paulo: Cosac Naify, 2015. 